\section{Projective Techniques for Understanding Cyber-Market Mavenism in Social Network Sites}

\author{
Milad Farzin 1 \\ Hossein Vazifehdust ${ }^{1}$ \\ Karim Hamdi ${ }^{1}$ \\ ${ }^{1}$ Department of Business Management, Science and \\ Research Branch, Islamic Azad University, Tehran, Iran.
}

Recebimento:

02/20/2019

Aprovaçáo:

03/03/2020

Editor responsável:

Prof. Dr. Helena Nobre

Avaliado pelo sistema:

Double Blind Review

\begin{abstract}
Purpose - The purpose of this study is to identify consumers called cyber-market mavens, whose viewpoints influence the attitude and behavior of other consumers. Furthermore, the research aims to create a better understanding of the antecedents and consequences of market maven behavior.
\end{abstract}

Design/methodology/approach - After creating rapport with them, the participants were given a blank sheet of paper and were asked to depict a cyber-market maven together with the environment in which he/she lives and the things he/she thinks. After drawing this, the participants were interviewed to answer questions associated with the picture's elements, and thematic analysis was used to interpret the data.

Findings - The data interpretation indicated seven factors that determine cyber mavenism as well as three factors affected by such behavior.

Practical implications - The study is useful for e-businesses wishing to target consumers who people perceive as good sources of marketplace information and who like introducing new brands to others, to use them as powerful sources in the context of co-producing products. In addition, cyber-mavens can help e-businesses amplify their new customer acquisition efforts by indicating which customer groups they should target with referral reward programs.

Originality/value - This study represents one of the first attempts to better understand how mavens behave in virtual world channels, and, by doing so, it better informs our understanding of an important group of consumers, namely cyber-mavens. The paper could be of value to marketers and advertisers who target cyber-markets.

Keywords - cyber-market mavens, social networks, thematic analysis, projective techniques, qualitative marketing research.

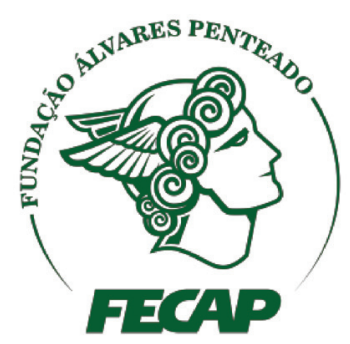

Revista Brasileira de Gestáo de Negócios

DOI:10.7819/rbgn.v22i3.4074 


\section{Introduction}

The term "market maven," which was first introduced by Feick and Price (1987) in marketing areas, refers to a consumer who is willing to diffuse general market information among their peers and is able to influence the attitudes and behavior of other consumers (Zhang \& Lee, 2014). Feick and Price (1987) describe such consumers as "individuals who have information about many kinds of products, places to shop, and other facets of markets, and initiate discussions with consumers and respond to requests from consumers for market information" (Feick \& Price, 1987, p. 85). Market mavens are an important group of consumers who engage in word-of-mouth (WOM) through their social bonds (Farzin \& Fattahi, 2018), and this has transformed them into a beneficial audience for businesses (Slama \& Williams, 1990; Yoshida, Miyazawa, \& Takahashi, 2014).

The literature on market mavens covers such topics as demographic profiles (Hoffman, 2015), personality characteristics (Clark, Goldsmith, \& Goldsmith, 2008; Ruvio \& Shoham, 2007), purchase alternatives (Yoshida et al., 2014), and drivers of market mavenism (Chelminski \& Coulter, 2007; Clark \& Goldsmith, 2005). In the above studies, there is no proper consensus on the profiling of mavens. In addition, the results of some of these studies are not compatible with the constructs (Flynn \& Goldsmith, 2017). Since, on the one hand, we sought to gain an understanding of the underlying reasons, opinions, motivations, context, and environment, and on the other we sought to develop hypotheses for quantitative research, we conducted a qualitative study to explore the lived experience of mavens. Furthermore, the market maven construct has been investigated in many Western countries (e.g. Chelminski \& Coulter, 2007; Clark et al., 2008; Goldsmith, Clark, \& Goldsmith, 2006; Goodey \& East, 2008; Ruvio \& Shoham, 2007), but since Iran is very diverse in terms of cultural variables such as individualism/collectivism, conspicuous and invidious consumption, and religious beliefs (Farzin \& Fattahi, 2018; Teimourpour \& Heidarzadeh, 2011), it is necessary for us to investigate the comprehensiveness of this concept.

Cyberspace provides ideal platforms that are appropriate for mavens, since these platforms facilitate social interactions and they increase the potential to disseminate market information in terms of speed and reduced expenses, particularly nowadays where we see the proliferating growth of cyberspace-based economies (Barnes \& Pressey, 2016). Even though the concept of "internet mavens" has attracted the attention of some researchers (Zhang \& Lee, 2014), the scientific community has so far not studied cyber mavens and nor has it attempted to expand their behavior in cyberspace, such as social networks (Barnes, Mattsson, \& Hartley, 2015). Considering the increasing importance of cyberspace and social media in consumption processes, studies on the behavior of cyber-market mavens have been considerably neglected. Cyberspaces have brought significant opportunities for marketing practitioners to disseminate product information and to expand virtual brands (Zhang \& Lee, 2014). Therefore, we consider extending the concept of market mavens to virtual environments and the cyber world in order to fill the research gap.

Unlike the studies carried out to date, the current study is well-timed for several reasons. First of all, mavens are exceptional distributers of product information and are considered to be one of the most important consumer groups to be targeted by product and services information (Parmentier \& Magematin, 2014). So their identification in online contexts is very important. Second, previous research has acknowledged the existence of internet mavens, therefore, the study of mavens in virtual worlds is a natural extension of this concept and it helps to understand the transferability of mavenism among various communication channels and the comprehensiveness of this concept. Virtual worlds are important environments in which different theories and principles should be 
explored (Barnes \& Pressey, 2016). This research is one of the few studies that examine this concept in cyberspace, and in this way it adds to the literature on the concept. Third, carrying out research in different environments can contribute to the comprehensiveness of the results on a phenomenon in the social sciences. By employing the phenomenological research tradition (Belk, Fischer, \& Kozinets, 2012), we tried to better understand the essence of the phenomenon of market mavenism in online environments.

\section{Theoretical Background}

Scholars have long advocated that marketers should focus their efforts on those consumers who exert disproportional influence upon other consumers' consumption decisions (Dawar, Parker, \& Price1996). Seen as credible, objective, and hence risk-reducing sources of product information, market mavens introduce new ideas and norms to other consumers and wield considerable sway over their behaviors (Clarket al., 2008; Kiani, Laroche, \& Paulin, 2016). Market mavens possess general market information and are willing to transfer it to others (Barnes \& Pressey, 2012), and as such, they are considered a more reliable source of product and brand information relative to other sources of marketing information (Chu \& Kim, 2011). Identifying market mavens and understanding their psychological and social makeup is critical for successful social network marketing campaigns, word-of-mouth marketing, and the diffusion of brand information (Iyengar, Van den Bulte, \& Valente, 2011).

Previous studies have focused on such constructs as individualism (Barnes \&Pressey, 2012; Edison \& Geissler, 2011), affinity for technology (Barnes \& Pressey, 2012; Geissler \& Edison, 2005), self-confidence (Chelminski \& Coulter, 2007; Clark et al., 2008), brand engagement and status consumption (Goldsmith, Flynn, \& Clark, 2012), perfectionism, (Walsh \& Mitchell, 2001), bargaining (Goldsmith,
Flynn, \& Goldsmith, 2003), altruism and commitment (Walsh, Gwinner, \& Swanson 2004), self-esteem (Clark \&Goldsmith, 2005), the need for uniqueness (Goldsmith et al.,2006), extraversion (Goodey \& East, 2008), risk taking (Edison \& Geissler, 2011; Ruvio \& Shoham, 2007), and diversity (Edison \& Geissler, 2011). In addition, areas such as decision-making styles (Walsh \& Mitchell, 2001; Wiedmann, Walsh, \& Mitchell, 2001), advertising (Abratt, Nel, \& Nezer, 1995; Belch, Krentler., \& Willis-Flurry, 2005; Chelminski \& Coulter, 2007), household income level (Christiansen \& Snepenger, 2005), and self-concept (Edison \& Geissler, 2011) have also been examined in mavenism studies. Considering the various concepts that have been explored in this field so far, this study seeks to identify the characteristics of maven behavior in virtual worlds.

The concept of electronic mavenism (e-mavenism), which has been derived from the concept of market maven, places emphasis on information searches and diffusion on the internet. The actions of traditional market mavens are characterized by a variety of behaviors that have evolved in the world of the internet and the internet itself has facilitated the manifestation of such behaviors. But e-mavenism is different, in terms of behavior, from traditional market mavenism. Such differences include, for instance, spending more time on the internet, reading emailed bulletins (newsletters) more carefully, and initiating discussions about family purchases (Walsh \& Mitchell, 2010). In addition, there is another difference between these two concepts that involves the type of dissemination of information, in that traditional mavens use verbal communication (Ruvio \& Shoham, 2007), while the word-of-mouth advertising of e-mavens is often in textual and written forms (Walsh \& Mitchell, 2010).

Due to the increasing proliferation of social media, there is an urgent need to examine how people engage in social media as well as to assess its role in shaping consumers' attitudes 
and behavior. Among the various types of social media, social network sites (SNSs) have received considerable attention from researchers, academics, and practitioners (Boyd \& Ellison, 2010; Lin \& Lu, 2011). SNSs have adopted the internet as a platform that enables online users to connect with each other through personal profiles, through which they invite friends and colleagues to access files and send instant messages to each other (Boyd \& Ellison, 2010). With their high levels of self-disclosure and social presence (Kaplan \& Haenlein, 2010), SNSs have enabled consumers to connect with each other by exchanging information, opinions, and thoughts about products, services, brands, stores, and companies (Farzin \& Fattahi, 2018). In addition, international brands have developed a new type of brand ambassadorship program that uses brand mavens to act as market information disseminators (Yang, 2013). For instance, in a campaign for new running shoes, Nike offered customers to try out a pair of brand-new sneakers in a virtual reality game and gave customers a oneof-a-kind experience worthy of social media buzz. Not only did this strategy result in a 7\% increase in share value for the company, but marketing experts also agree that it was one of the top 20 marketing campaigns of the year (Adweek, 2018).

Furthermore, cyber-mavenism can involve a variety of online personalities that are more diverse than in the case of e-mavenism. That is to say, people enter social networks with unreal names or special avatars, and in cyber space and virtual worlds there is more interpersonal interaction, so they may become more or less sociable. In addition, cyber mavens may create much stronger and a greater number of social ties relative to e-mavens, given the nature of social networks (Farzin \& Fattahi, 2018). Moreover, with regard to the presentation and dissemination of information, social media platforms have provided people with free access to unprecedented facilities. For instance, consumers can easily share their own video clips - even live - showing them using products, they can make video calls, and by running competitions, they can increase their audience and their social circles will progressively multiply. It is in this context that the present research proceeds to explore the key factors involved in cyber-mavenism behavior and to ascertain the possible consequences of such behavior.

\section{Methodology}

In the present research, the picture drawing technique was used to explore the lived experience of the informants regarding the concept of cybermarket mavenism. Asking people to draw a picture of an idea, object, or event is a research technique used by researchers for different purposes. Picture drawing studies have enabled researchers to examine mental states, cognitive abilities, and the essence of phenomena (Levy, 1950). Recently, the picture drawing technique has been applied by researchers to study individuals' perceptions of media and consumer-related behaviors in such instances as images of famous people (Gauntlett, 2005), marketplace perceptions (McNeal, 1992), visual memory regarding product packages (McNeal \& Ji, 2003), children's perceptions of their material belongings (Chan, 2006a), and people's perceptions of brands (Chan, 2006b), indicating it as an effective method for conducting exploratory research and finding out about the nature of phenomena. It is noteworthy that this technique is normally accompanied by short interviews, which are conducted to further clarify and analyze the themes under consideration. The research procedures are explained in Appendix A.

The participants in this study are consumers who, from the perspective of others, are mavens in the cyber environments. Thus, to select individuals considered as cyber mavens, the primary participants were selected based on the judgment of other consumers, and then a sequential and snowball approach was used to continue the sampling. Having found several market mavens in cyber environments, they were asked to introduce other individuals who could 
provide us with relevant information. Using this procedure, the research sample was selected and the interviews with the sample respondents continued until reaching data saturation.

In this study, the validity and reliability of the study were assessed by the Lincoln and Guba (1985), Denzin and Lincoln (1989, 1994 , 2005), and Maxwell $(1997,2004)$ criteria. Using the "prolonged engagement," "triangulation," "member check," "using standard methods" (e.g. thematic analysis), and "thick description" strategies, we met the Guba and Lincoln criteria of trustworthiness. Also, by applying "methodological triangulation" (e.g. picture drawing and interviews), "data triangulation" (e.g. images and text), and "investigator triangulation" (e.g. using a second interviewer and analyst), we attempted to meet Denzin's triangulation criteria, which are among the most popular validation criteria in qualitative research. In addition, we attempted to satisfy Maxwell's (1997, 2004) qualitative validity criteria (e.g. internal validity, interpretative validity, and descriptive validity) through such strategies as "investigator triangulation," "participants' feedback," "lowinference description," and "data saturation." For instance, by spending adequate time observing various aspects of a setting, speaking with people, and developing relationships and rapport with members of the culture, we attempted to satisfy the "prolonged engagement" criterion. Also, for "member check" and "participants' feedback" at each stage of the analysis, the interviewer's impression was explained to the participant and the errors were corrected. Next, after conducting and implementing the research, the results were communicated to the participants and their feedback was collected. In addition, the least amount of intervention took place in the descriptions, so the descriptive phrases and the pictures drawn by the participants were reported as they were to satisfy the "low-inference description" criteria. Data saturation has been referred to as a justification for sample size in thematic analyses, and in this study, the sampling was terminated as soon as there were no additional concepts observed. Based on the review method during the coding and the use of a second interviewer, the reliability was confirmed of the research tool used in this study. Inter-coder validity was also used to indicate consensus between the different coders (Chan, 2006; Marton, 1986).

The data analysis was carried out simultaneously with the data collection. For the data analysis, a thematic analysis was used, which involves data coding and analysis, aiming to find out what the data say. There are various methods used for thematic analysis. In the present research, Depoy and Gitlin's (2015) approach to thematic analysis was used, which involves four sub-processes: engaging in simultaneous deductive-inductive thinking, constructing and composing categories, categorizing at higher levels of abstraction, and discovering underlying meanings of themes (DePoy \& Gitlin, 2015). Firstly, to view the research subject both from inside and outside the context, we reviewed the literature as well as observing the lived world of the informants. Then, we looked through the pictures as a whole to have a comprehensive sense of the data and then read and re-read the picture elements very carefully. Secondly, for each picture, we labeled relevant elements, words, phrases, or facial expressions of market mavens. This technique helped us to code the data based on the participants' views. Thirdly, to enrich the categories and the theme construction, our coding process used a hybrid approach, balancing inductive coding of themes emerging in our informants' pictures, and deductive coding derived from our theoretical framework. After this, all the created codes were examined and classified into themes that represented a specific and unique idea. Fourthly, to understand underlying meanings and describe the connections between these themes, we conducted interviews with the research participants and discussed their picture elements. 


\section{Findings}

\section{I Simultaneous engagement in deductive-inductive thinking}

At this stage, adopting an analytical approach before, during, and after the interviews, we sought to build a more comprehensive understanding of the core research concept within the informant's micro real world. The analysis involved, on the one hand, a review of the research literature and prior work on mavenism, and on the other hand, observation of the world in which the informants found themselves. In addition, we established links to these individuals in the social networks and groups of which they were members in order to better monitor their information dissemination process. This analysis enabled us to view the research subjects both from inside and outside the context (emic vs. etic), which significantly helped the process of initial coding, theme identification, and interpretation of concepts.

\subsection{Theme construction and composition}

At this stage, following simultaneous deductive-inductive thinking, we began with identifying the visual elements present in the pictures drawn by the informants. This task was carried out by the researcher and an MBA student from Islamic Azad University acting as the research assistant. They each independently coded the picture elements and identified the categories. 34 visual elements of objects and facial expressions of people in the pictures were identified and coded. One of the images that have both more themes and a good resolution for printing is shown in Figure 1. The coding reliability of the 34 visual elements among the results of the two researchers was 0.89 , which is obtained by dividing the compatible code given between the two researchers into all existing codes (Chan, 2006). In total, 34 visual elements were identified in all of the pictures (See Appendix B).

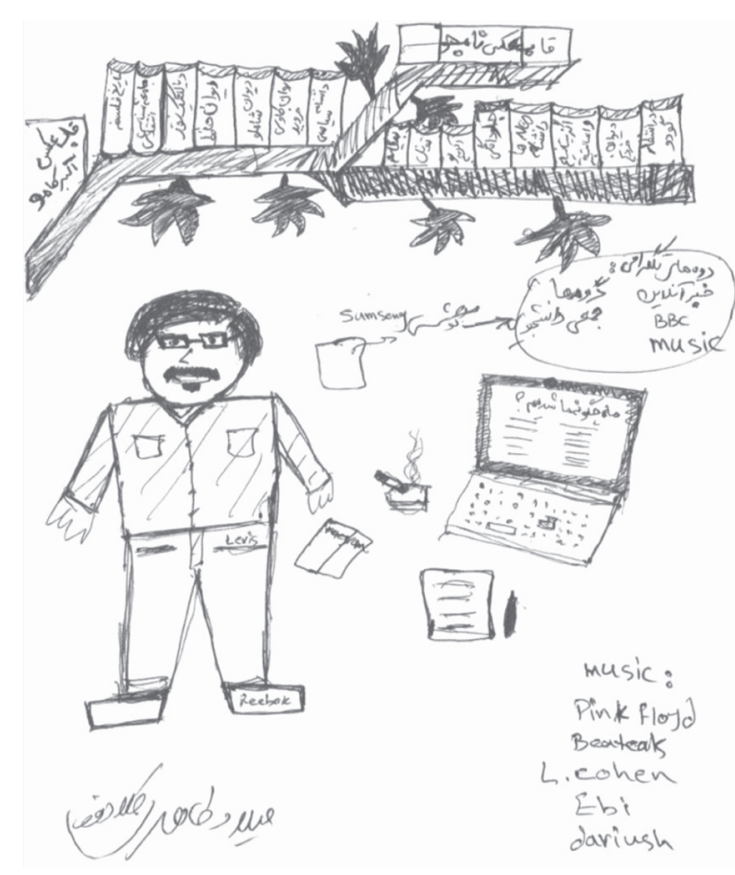

Figure 1. An example of a picture drawn by the research informants

\subsection{Categorization at higher levels of abstraction}

At this stage, using an analytical process, we merged the categories obtained in the previous stage and enriched them. To do this, based on the investigations and the obtained knowledge and findings regarding the informant's lived world from the previous stage, we searched for the terms and concepts in the marketing literature which covered the identified codes and categories that could be representative of the codes drawn by the informants. After categorization at higher levels of abstraction inspired by the literature, the respondent validation technique (informant feedback) was used to make sure that the enrichment of the categories and the theme construction were credible and applicable. For this purpose, we checked the assumptions with some of the informants. The initial results regarding the categories, their numbers and grouping at higher levels of abstraction, and their enrichment are presented in Table 1. In Figure 2, we show the themes extracted from the interviews after reaching thematic saturation in words cloud, given their repetition in the pictures. 
Table 1

The results of the initial coding: categories and their frequency and grouping at higher levels of abstraction

\begin{tabular}{|c|c|c|}
\hline Categories & Frequency & Themes \\
\hline Mobile & 16 & \\
\hline Tablet & 3 & Online social capital \\
\hline Social media and networks & 10 & \\
\hline Laptop & 14 & \multirow{14}{*}{ Knowledge level } \\
\hline Computer & 3 & \\
\hline Information & 15 & \\
\hline Internet & 12 & \\
\hline Modem and Wi-Fi & 4 & \\
\hline Newspaper & 2 & \\
\hline TV & 3 & \\
\hline Book & 12 & \\
\hline Eyeglasses & 9 & \\
\hline Search \& inquiry & 14 & \\
\hline Stationery tools & 3 & \\
\hline Satellite & 2 & \\
\hline Airplane & 2 & \\
\hline Planet Earth & 3 & \\
\hline Branded goods & 17 & \multirow{2}{*}{ Engagement with brands \& products } \\
\hline Big brain & 3 & \\
\hline Tree and leaves & 2 & \multirow{4}{*}{ Moral obligation } \\
\hline Drip irrigation & 1 & \\
\hline Fuel consumption & 1 & \\
\hline Accountability and commitment & 4 & \\
\hline Billboard & 3 & \multirow{3}{*}{ Advertisement engagement level } \\
\hline Advertising & 2 & \\
\hline Website advertising & 7 & \\
\hline Technologies of the day & 11 & Affinity for new technology \\
\hline Problem solving ability & 16 & \multirow{2}{*}{ Self-efficacy } \\
\hline Confidence (self-confidence) & 4 & \\
\hline Happy and smiling face & 17 & \multirow{2}{*}{ Altruism } \\
\hline Enjoy helping & 8 & \\
\hline Dissemination of information $\&$ experience & 14 & Experience, information, and knowledge sharing \\
\hline Different brands & 5 & Brand switching behavior \\
\hline $\begin{array}{l}\text { Economic issues: money, dollars, gold coins, } \\
\text { wealth, and capital }\end{array}$ & 13 & Frugality behavior \\
\hline
\end{tabular}




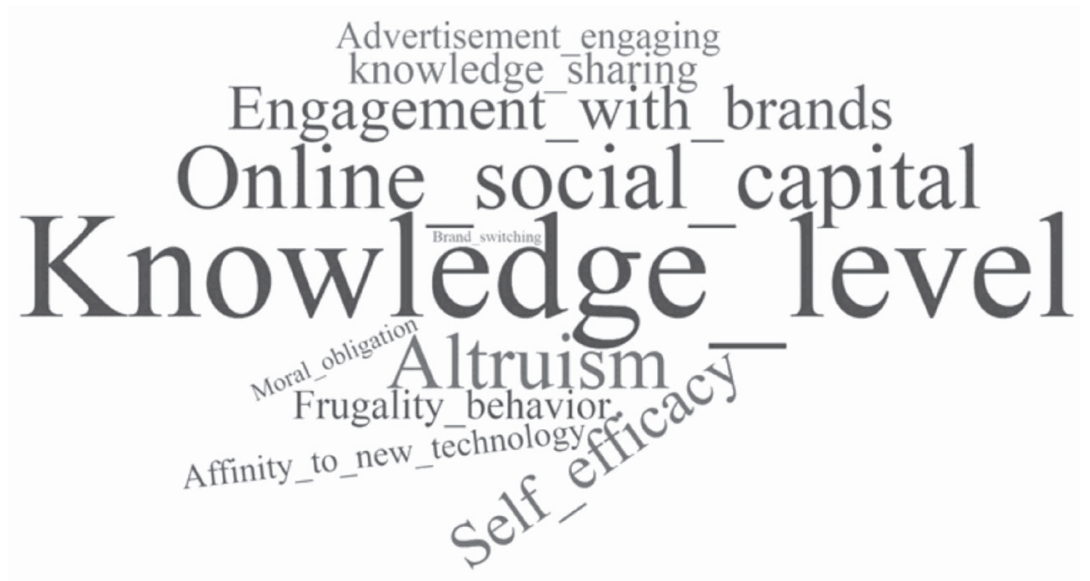

Figure 2. The word cloud constructed from the themes extracted in the thematic analysis

\subsection{Discovering underlying meanings and themes}

After final refinement of the themes, our aim was to ".identify the 'essence' of what each theme is about" (Braun \& Clarke, 2006). So, at this stage, we interviewed the informants to clarify what the theme is saying. If there are subthemes, how do they interact and relate to the main theme? How do the themes relate to each other? With this approach, we attempted to discover underlying meanings and illustrate the relationships between themes.

The theme "online social capital" incorporates the categories of mobile, tablet, and social media and networks, which were indicated a total of 29 times in the pictures. In describing these categories, the interviewees believed that cyber-market mavens use their smart phones and tablets to search for information about products and brands and disseminate their findings, and they interact and are in contact with their social circles through their smart phones or tablets. For instance, Milad says:

“...people are able to read the news online and form telegram-like groups or become a member of existing groups and give their comments on products and brands. Or anyone who has a question can pose it and these mavens answer it using their previous experience or by quickly searching websites they find an appropriate answer to the person's question."

In regard to the theme "knowledge level," a total of 13 categories were identified that the informants in the interviews referred to as the main drivers of cyber-market mavenism. According to the informants, market mavens have adequate general information regarding products and brands. The informants, in addition, believed that cyber-market mavens have adequate knowledge on the use of computer and internet technologies, especially searches regarding product features, and they have expertise on how to utilize online communities, media, and networks. For instance, Javad says:

"I think the world has become a village for me, so for everything that I need information on, I only need to sit at my laptop and open a page, for example, a brand name about which I want to find information on Google ... guys like me use their time properly ... even if I'm going to buy a good physically in the marketplace, I first do a lot of research about it on networks and websites on the internet. You can even buy your airplane and travel tickets and reserve your hotel on 
the internet today, and you can specify in advance the attractive sights of the place where you want to travel."

The third theme, "engagement with brand," was derived from the pictures drawn from the two categories of "products and brands" and "complexity and big brain." From the viewpoint of the informants, market mavens are, to a great extent, concerned with brands, particularly cyber mavens, who engage in searching in virtual and online environments. As one of the research informants, Zahra, noted:

"Product brand is very important .... In my view, the money we give should be in proportion to the product brand we buy .... My mobile phone is an Apple 6 but my tablet is a Samsung because they provide more than my desired level of efficiency. My laptop is HP brand. At home, Sony used to be the TV brand of choice that we always bought, but this time when we wanted to buy a new TV set, I searched a lot and found out that LG was the best choice, given its price and quality...."

The theme "moral commitment" was identified by four categories with a cumulative frequency of 8. According to one interviewee, moral commitment was one of the factors motivating them to collect market information and help their friends and close ones with their decision making and choice of products. For example, Milad says:

"I am a supporter of the environment and I consider it my duty to use products and brands which are environment-friendly when I am providing information to my friends or I myself am making a purchase."

And Sahar also says:

"I think market mavens are committed and responsible .... When my friend asks me about a product or a brand, I try to collect the best information that may be of any use, only because they count on me, otherwise, there is no financial benefit in it for me."

In the group "engaging level of advertisement," the informants referred to three categories from the pictures, with a total of 12 visual elements. Some of the interviewees maintained that the advertisements (promotion messages) they saw influenced their willingness to disseminate the message on a product or brand among their friends and other members of their social groups. For instance, Sahar says:

“...on many occasions when I'm not working, I check product advertisements on websites...Some of these advertisements are really tempting, such as those about weight loss."

Furthermore, in the group "affinity for new technology," the informants referred to 11 visual elements in the pictures drawn. They believed that the inner tendency of individuals to choose state-of-the-art technologies may cause them to more intensely engage in information collection and dissemination, leading to their expertise. This is especially the case in the present era in which information is diffused among members of society at a high rate and very low cost. On this point, Zahra says:

"...someone who is a market maven is interested in studying and acquiring information regarding the role of modern technologies in helping achieve their goals, in which the creation of wealth could be the most important one."

And Nassim also notes:

“...in my drawing, the figure is searching the Google page for information about new technologies ... he can check the 
news on the latest technologies to find out what technological changes are taking place ... for example, the launch of a new iron. You only need to put clothes in it, and they will be ironed automatically."

Concerning the theme "self-efficacy," two categories, i.e. "problem solving" and "selfconfidence," were identified by the interviewees in the pictures, being referred to 20 times in total. The informants were of the view that market mavens, in terms of knowledge and skills, have achieved a kind of self-efficacy which they can use in their buying decisions and/or helping their friends in social networks, eventually leading to their greater expertise in market-related issues. For example, Babak says:

"I look for knowledge and information, and I think that I have the ability needed for gathering market information and solving the problems of my friends regarding purchases of products."

And Zeinab says:

“...when choosing products and brands, I decide myself and rely on my experience and the information I search."

For the theme "altruism," the interviewees referred to "enjoy helping" and "happy and smiling face" as the indicators, with a total frequency of 25 in the pictures. The informants maintained that market mavens enjoy disseminating their market knowledge and experience and feel happy that they can give advice to their friends regarding their buying decisions and help them with their choices, and this gives them the motivation to get increasingly more involved in collecting market information and extending their knowledge regarding products and brands. On this point, Milad says:

"I feel proud of having a lot of information on the market and products and others seek my advice and guidance, and this gives me pleasure."

\section{And Alireza says:}

"I send helpful information about products and brand to my good friends, which gives me a sense of usefulness."

In the pictures drawn, the interviewees referred a total of 14 times to dissemination of their information and experience of the market, products, and brands among their friends, acquaintances, and social networks, especially Telegram. They believed that they should share the useful information they obtain through searching for products and brands with their friends. For example, Zakieh says:

"I think those who are market mavens can't help it (she laughs), they willy-nilly talk about everything and incessantly distribute the information they have, in the office, in social networks, etcetera."

In the interviews conducted, there are 5 pictures in which the informants show different brands to a person or in their thought bubbles are thinking about different brands. They are of the view that market mavens, especially in cyber environments with faster and cheaper access to information, pay attention to new and different brands and welcome new experiences, not being very attached and loyal to particular brands, unless the brand is a market leader and pioneer in all areas. In this regard, Milad says:

“...to my mind, loyalty to a specific brand is not very wise ... one should test new brands, or at least, read their information. They may offer a better product. It is like when you always go to one café or restaurant; I think the Muscle of Mehrdad restaurant is very good, but if I want to have a kabab-barg, I'll surely go to Pedarbozorg restaurant." 
In the pictures obtained from the interviews, there were 13 visual elements which signified economic concerns regarding money, dollars, (gold) coins, and the like. The interview with the informants revealed that the cybermarket mavens behaved thriftily in their buying decisions. They stated that their expertise in market issues enables them to save costs for themselves, their family, and their friends. In this regard, Javad notes:

“...at this time, one must make smart purchases. Nothing is wrong with checking the prices of all stores and buying from the store that gives you the product at the lowest price... Each consumer has the right to purchase goods at the best price."

\section{General Discussion}

Given the fact that market mavens communicate their WOM through cyber spaces such as social networks, their advertising has a strong influence over the perceptions, attitudes, and behavior of other consumers. Therefore, understanding the behavior of market mavens would significantly contribute to the formulation of advertising strategies, especially regarding the target audience of businesses. In this study, we attempted to provide an insight into the behavior of this type of consumer.

The study identified two groups of attitudinal, personality, and behavioral characteristics among cyber-market mavens in response to the research question, using the picture drawing technique. The first group concerned the antecedents, which indicate the constituent elements of people's willingness for such behavior, comprising online social capital, knowledge level, engagements with brands, moral commitment, affinity for new technology, selfefficacy, and altruism. The second group refers to features resulting from such behaviors and tendencies, which include market information and experience sharing, brand switching behavior, and frugality behavior.
The results of the interviews held with the informants indicated that cyber-market mavens have extensive social capital in cyber space, creating friendships and work-related bonds on social network websites. They may also become a member of other friendship groups and networks in which they interact with other consumers or their peers, helping them in their buying decisions, which is in line with the results of other researchers (Flynn \& Goldsmith, 2017; Zhang $\&$ Lee, 2014). On the other hand, many of the interviewees referred to books, the library, searches on the internet, or Wikipedia in their pictures and believed that such individuals must read a lot and have adequate knowledge regarding products, brands, computer and internet technologies, as well as social networks, since, in their view, having knowledge in these areas is a necessary condition for cyber-market mavenism, These findings are consistent with the results of other research in this sphere (Barnes \& Pressey, 2016; Kiani, et al., 2016). According to the interviewees, market mavens are mentally concerned with brands and products, and this involvement can be much greater in cyber worlds, as they have faster access to information and they do not pay much for this information. In addition, they believe that these individuals think of the various brands that offer a product when they see it. They consider mental involvement with the brand as one of the characteristics of market mavens, which has an impact on their market expertise. It is logical to imagine that consumers who use products and brands to express their image also have an incentive to learn and gain knowledge of the desired brand on the market. Flynn and Goldsmith (2017) stated that market mavens have a great awareness of products and brands, and Zhang and Lee (2014) noted that market mavens have a large evoked set of brands and products. The researchers expressed that engagement with brands is positively correlated with market mavenism behavior. On the other hand, they stated that market mavenism is associated with product categories that are indicative of social 
and prestige concerns (Goldsmith et al., 2006).

Furthermore, the interviewees noted that they feel joy and satisfaction in helping their peers and other consumers by sharing their information and knowledge with them in virtual communities and cyber worlds such as social networks. Market mavens that act for altruistic and humanitarian motives tend to give their information, knowledge, and experience to other members without any expectations. Market mavens can benefit other members of social networks by helping them in their buying decisions. O'Sullivan (2015) stated that market mavens are involved in a spectrum of marketleading behaviors that include reducing the risks associated with other consumers' consumption decisions, and Goldsmith et al. (2012) pointed out that market mavenism is associated with a sense of commitment to sharing information, the willingness to help others, and the pleasure of informing others about products.

Information and knowledge exchange between members of social networks strengthens their sense of unity and belonging as members of one and the same community, so they feel committed to exchanging information. The boundary of commitment to social networks can extend to a sense of moral commitment to other members due to common membership of one community. This sense of commitment among market mavens could be even more pronounced. This means that when market mavens have commitment to those that are members of their social networks, they see it as their duty to help other members. Kiani and colleagues (2015) mentioned that people with a stronger sense of responsibility would be more likely to take action to defend the interests of other consumers, even if they would have to spend time and energy on it. Flynn and Goldsmith (2017) stated that market mavens share their knowledge with other consumers, and are therefore very useful as a reliable source of information, and this tendency and inclination is consistent with their sense of duty and conscientiousness. Zhang and Lee
(2014) also asserted that market mavens feel compelled to share information with members of the community they are members of.

The interviewees stated that knowledge self-efficacy can be considered as a self-motivating factor which helps knowledge development in virtual communities and cyber environments such as social networks. The research results indicated that the market maven's perception of their abilities to collect useful information about products and brands affects their willingness to engage in such behaviors. As the level of selfefficacy rises, individuals become more willing to help others, because they have confidence that their help will be effective. Knowledge selfconfidence can work as an intrinsic motivator of mavens and encourage them to disseminate their information and knowledge on the social networks they are members of. These findings are consistent with the results of Farzin and Fattahi's (2018) research. Zhang and Lee (2014) held that market mavens have high self-esteem and self-efficacy and feel confident. In addition, Goldsmith et al. (2012) indicated that market mavens are confident in their ability to obtain and make use of market information. Clark et al. (2008) stated that the willingness of market mavens to serve as market-experienced individuals shows that they trust their own capability to acquire and appreciate market information.

According to the research interviewees, market mavens embrace new technologies and enjoy the associated learning process and challenges, and considering the innovationdriven nature of market mavens and their evident interest in new products, they tend to disseminate information on new products and brands among their peers and other consumers in cyber space. Affinity for technology could be defined as the extent to which an individual likes or seeks to learn about new technologies or is involved with them. Consumers vary in their propensity towards technology and the adoption of new technologies. While some individuals worry about such developments and changes (Rogers, 
2003), other consumers, such as market mavens, are more open to new technologies. Barnes and Pressey (2016) claimed that mavens are inherently innovative and are more likely to be the first to examine and accept new products. And through their purchases they want to reveal their excellence and need to stand out from other individuals.

In the view of the interviewees, people should test new brands and products, because the companies operating in a particular class of product may excel in offering some products and be inefficient in offering others. Meanwhile, some of the informants were of the view that quality can vary over time and, as a result of technological changes, the market leader in the respective industry may change. Flynn and Goldsmith (2017) stated that market mavenism is positively related to brand exchanging behavior. In addition, Goldsmith et al. (2012) pointed out that market mavenism is related to the need for diversity and is able to build multi-brand loyalty.

The informants also pointed out that market mavens consider a product's cost/benefit given its price/quality, and in many instances, they purchase products during auctions (public sales) or discount announcements by companies, as they believe buying cheap is an art. Barnes and Pressey (2016) stated that mavens enjoy learning about new products and services, collect coupons from newspapers and magazines, and are generally involved in purchasing behavior. In addition, Flynn and Goldsmith (2017) noted that market mavensim is positively connected with cost-saving behavior. Mavens are smart buyers who engage in bargaining, collecting discount coupons, and comparing shopping centers to get the best deals. Zhang and Lee (2014) also maintained that market mavens purchase goods from discount stores and use discount coupons.

The dissemination of market information and experience is a behavioral consequence of market mavenism. That is to say, these individuals spread the information they believe can be used by other individuals or groups in their social networks. In this regard, the informants claimed that they have obtained their widely diverse market information by studying advertisements of companies, and the attraction and appeal of the advertising and advertising channels through which products and brands were introduced to them played a significant role in the scale (extent) of their information diffusion. Zhang and Lee (2014) held that market mavens actively seek ads and pursue promotional information from personal resources and mass media. In addition, Goldsmith et al. (2012) argued that market mavens mainly focus on ads. Chelminski and Coulter (2007) also stated that market mavens are well-informed about the market, pay attention to marketing information and ads, and are interested in sharing information with others.

\section{Conclusion}

Following a simultaneous analysis of the interview texts and the existing literature, those constructs and variables were extracted that could properly capture the categories derived from the research. At this stage, we again used the participants' feedback for interpretative validity in order to make sure that the selected construct properly covered the intended category. Next, by examining the interviews and the prior research and theoretical background (engagement in deductive-inductive thinking), we explored the likely relationships between the constructs and variables identified in the previous stage to formulate the research assumptions and develop a theoretical model, and the research conceptual model was drawn based on the existing data and information. For interpretative validity, this model was shown to the informants to give their feedback, based on which the model was further modified. In fact, at this stage of the research, in light of the developed hypotheses and model, we sought to answer the main research question regarding the main antecedents influencing and implications influenced by cyber-market mavenism. 


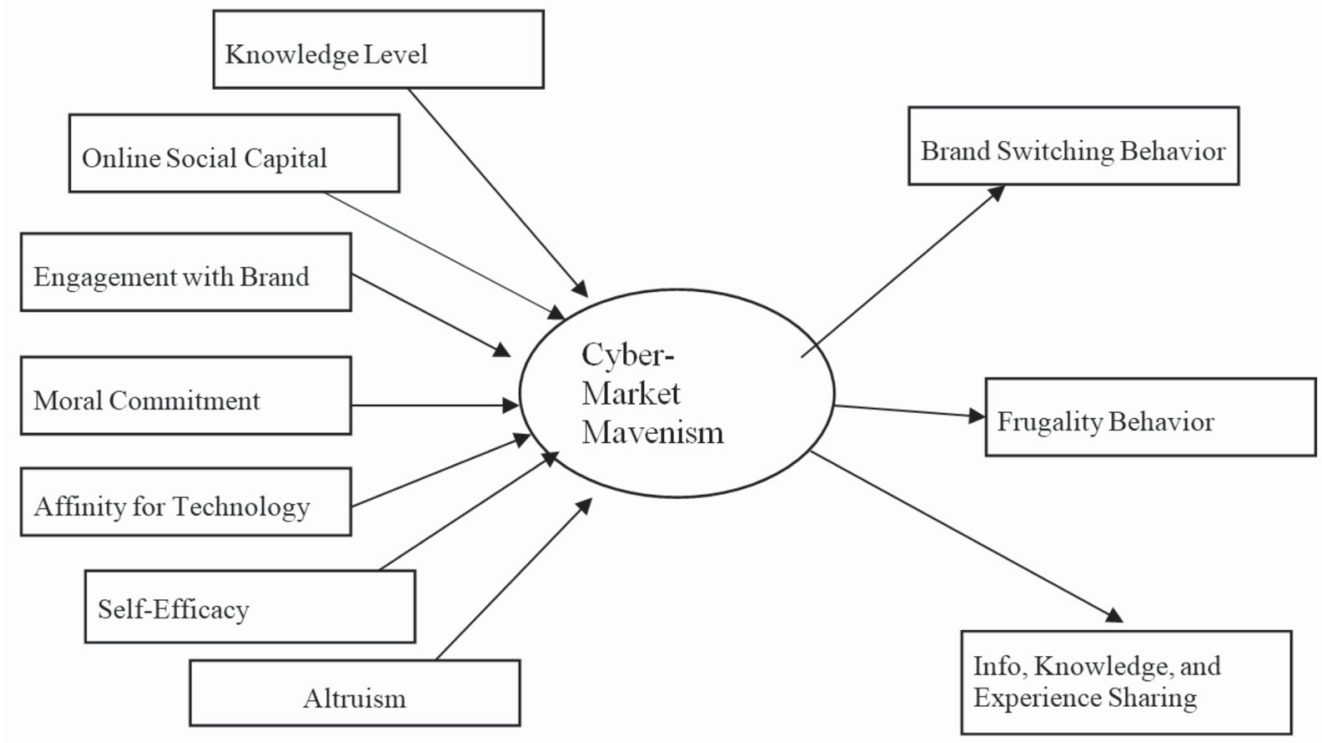

Figure 3. Research conceptual model representing the themes and their relationships

\section{I Implications}

While the extant research considerably increases our understanding of mavenism, it is largely focused on how mavenism behavior contributes to shaping behavioral and attitudinal patterns in the physical context, and not in the virtual one. This research attempts to fill the existing gap by simultaneously inquiring into the factors that contribute to cyber-mavenism and the important factors that are affected by it.

We believe that the present research and its findings significantly contribute to the conceptual understanding of mavenism behaviors in social networks and online contexts. This study contributes to the existing literature in several ways. Firstly, most of the prior research in the field of mavenism is focused on the impact of mavenism on consumer buying decisions and provides little insight into the causes of cybermavens' willingness to spend their time sharing their experiences regarding products and brands with other consumers in the context of social networks. By providing a theoretical model of the antecedents and consequences of mavenism, this study attempts to enrich the existing literature on the topic.
Secondly, our findings help people working in the marketing sectors of companies and advertising agencies to develop their advertisements in accordance with cyber-mavens' characteristics and thereby extend their messages' reach among consumers. Social networks create a channel to build and establish relationships between consumers and brands. Marketing and advertising practitioners must try to identify cyber-mavens and encourage them to engage in positive eWOM. In addition, social networks allow marketing and advertising practitioners to have access to a large number of consumers at high speed and low cost. This further enables these practitioners to adopt personalized and customized marketing strategies for targeting cyber-mavens, and subsequently, the target consumers of the company's products and brands. They may use, for example, techniques to build trust or use advertising messages which are informative and create awareness and thereby enhance people's sense of knowledge self-efficacy.

Thirdly, by tracking the profile of cybermavens and finding out when and how they show or express willingness to engage in eWOM, marketing practitioners can use the variables 
involved in shaping their mavenism behaviors and provide the ground for establishing long-term, two-way relationships between cyber-mavens and brands. Another noteworthy issue concerns social networks themselves. Providers of these platforms need to improve their interactive features. Such improvements would stimulate the sense of belonging to a group, moral commitment to a group, and engagement with brands among group members. By introducing mechanisms that identify the individuals engaged in giving useful advice to other members and allowing the readers of the comments to express their gratitude to the writers of the advice, these providers can stimulate the sense of altruism, the sense of moral commitment, and the self-efficacy of cybermavens. Moreover, today, with public access to social networks, marketers are able to constantly monitor the eWOM for their brands and those of competitors (Farzin \& Fattahi, 2018). These platforms allow marketing practitioners to progressively employ novel communication tools to engage mavens with products and brands and enhance their knowledge regarding them. For instance, they may design online games in social networks related with the company's products and brands in order to engage mavens and induce them to generate eWOM.

\subsection{Limitations and future research directions}

In this research, a qualitative method is used to carry out the analyses. It would be better to test the assumptions presented in this study in a quantitative study in order to generalize the results of the research to larger communities. In addition, the relationships between the constructs at different levels, as well as the different levels of ad engagement according with the extent of the desire to disseminate information, could be measured through semi-experimental testing and manipulation of the variables. The existing literature on cyber-market mavenism is very limited, and we hope to extend the research by studying this concept in various fields. The high cost of implementing research and data collection prevented the consideration of different types of industries, social networks, and respondents. Consequently, in this study we could not take advantage of comparative studies. We suggest that future studies examine market mavens in various industries such as tourism, healthcare, high-tech, or low-tech industries. These could even consider the behavior of mavens among various virtual networks and examine the impact of the networks on market mavenism behavior, thus providing gains for the policy makers of these platforms. With regard to the ethnic diversity in Iran, cross-ethnic research could be conducted to see whether ethnic stereotypes have any impact or not on the manifestation of such behavior among consumers. Furthermore, because of the prevalence of social networks among different ages nowadays, researchers could investigate the impact of the cross-generational gap between individuals and see whether the age limit placed on individuals is meaningful or not with respect to the nature of social networks. Finally, it should be noted that although the number of interviews conducted in the qualitative section was more than the standard mentioned in the sources, and the interviews were stopped when they reached data saturation, the more interviews there are, the more this increases the accuracy that is required to compare the results of the data.

\section{References}

Abratt, R., Nel, D., \& Nezer, C. (1995). Role of the market maven in retailing - A general marketplace influencer. Journal of Business and Psychology, 10(1), 31-55.

Adweek (2018). Nike shoppers can now test-run sneakers on a treadmill hooked up to a video game. Retrieved from http://https://www.adweek. com/creativity/nike-shoppers-can-now-test-runsneakers-on-a-treadmill-hooked-up-to-a-videogame.html

Barnes, S. J., Mattsson, J., \& Hartley, N. (2015). Assessing the value of real-life brands in virtual 
worlds. Technological Forecasting and Social Change, 92, 12-24.

Barnes, S. J., \& Pressey, A.D. (2012). In search of the "meta-maven": An examination of market maven behavior across real-life, web, and virtual world marketing channels. Psychology \& Marketing, 29(3), 167-185.

Barnes, S. J., \& Pressey, A. D. (2016). Cybermavens and online flow experiences: Evidence from virtual worlds. Technological Forecasting and Social Change, 111, 285-296.

Belch, M. A., Krentler, K., \& Willis-Flurry, L. A. (2005). Teen internet mavens: Influence in family decision making. Journal of Business Research, 58(5), 569-575.

Belk, R., Fischer, E., \& Kozinets, R. V. (2012). Qualitative consumer and marketing research. London: Sage Publications Ltd.

Boyd, D.M., \& Ellison, N.B. (2010). Social network sites: definition, history, and scholarship. IEEE Engineering Management Review, 38(3), 16-31.

Braun, V., \& Clarke, V. (2006). Using thematic analysis in psychology. Qualitative Research in Psychology, 3(2), 77-101.

Chan, K. (2006a). Exploring children's perceptions of material possessions: A drawing study. Qualitative Market Research: An International Journal, 9(4), 352-366.

Chan, K. (2006b). Young consumers and perception of brands in Hong Kong: A qualitative study. Journal of Product \& Brand Management, 15(7), 416-426.

Chelminski, P., \& Coulter, R.A. (2007). On market mavens and consumer self-confidence: A cross-cultural study. Psychology \& Marketing, 24(1), 69-91.
Christiansen, T., \& Snepenger D. (2005). Information sources for thrift shopping: is there a "thrift maven"? Journal of Consumer Marketing, 22(6), 323-331.

Chu, S. C., \& Kim, Y. (2011). Determinants of consumer engagement in electronic wordof-mouth (eWOM) in social networking sites. International journal of Advertising, 30(1), 47-75.

Clark, R.A., \& Goldsmith, R. E. (2005). Market mavens: Psychological influences. Psychology \& Marketing, 22(4), 289-312.

Clark, R. A., Goldsmith, R. E., \& Goldsmith, E. B. (2008). Market mavenism and consumer self-confidence. Journal of Consumer Behaviour, 7(3), 239-248.

Dawar, N., Parker, P.M., \& Price, L.J. (1996). A cross-cultural study of interpersonal information exchange. Journal of international business studies, 27(3), 497-516.

Denzin, N. K. (1989). The research act: A theoretical introduction to sociological methods. New Jersey: Routledge.

Denzin, N. K., \&Lincoln, Y. S. (1994). The Sage handbook of qualitative research. London: Sage publications.

Denzin, N. K., \&Lincoln, Y. S. (2005). The Sage handbook of qualitative research. London: Sage publications.

DePoy, E., \& Gitlin, N. L. (2015). Introduction to Research: Understanding and Applying Multiple Strategies. Missouri: Elsevier Health Sciences.

Edison, S.W., \& Geissler, G.L. (2011). An investigation of negative word-ofmouth communication among market mavens. Journal of Marketing Communications, 11(2), 73-94.

Farzin, M., \& Fattahi, M. (2018). EWOM through social networking sites and impact on purchase intention and brand image in Iran. 
Journal of Advances in Management Research, 15(2), 161-183.

Feick, L. F., \& Price, L. L. (1987). The market maven: A diffuser of marketplace information. The Journal of Marketing, 51(1), 83-97.

Flynn, L., \& Goldsmith, R. E. (2017). Filling some gaps in market mavenism research. Journal of Consumer Behaviour, 16(2), 121-129.

Gauntlett, D. (2005). Imagined worlds of stars and celebrities: $A$ art project in association with Tate Liverpool. Retrieved from www.theory.org. uk/david/artproject.htm

Geissler, G. L., \& Edison, S. W. (2005). Market mavens' attitudes towards general technology: Implications for marketing communications. Journal of Marketing Communications, 11(2), 73-94.

Goldsmith, R. E., Clark, R. A., \& Goldsmith, E. B. (2006). Extending the psychological profile of market mavenism. Journal of Consumer Behaviour, 5(5), 411-419.

Goldsmith, R. E., Flynn, L. R., \& Clark, R. A. (2012). Motivators of market mavenism in the retail environment. Journal of Retailing and Consumer Services, 19(4), 390-397.

Goldsmith, R. E., Flynn, L. R., \& Goldsmith, E. B. (2003). Innovative consumers and market mavens. Journal of Marketing theory and practice, $11(4)$, 54-65.

Goodey, C., \& East, R. (2008). Testing the market maven concept. Journal of Marketing Management, 24(3-4), 265-282.

Hoffman, R. (2015). Visionary competence for long-term development of brands, products, and services: The trend receiver concept and its first applications at Audi. Technological Forecasting and Social Change, 101, 83-98.
Iyengar, R., Van den Bulte, C., \& Valente, T.W. (2011). Opinion leadership and social contagion in new product diffusion. Marketing Science, 30(2), 195-212.

Kaplan, A. M., \& Haenlein, M. (2010). Users of the world, unite! The challenges and opportunities of Social Media. Business horizons, 53(1), 59-68.

Kiani, I., Laroche, M., \& Paulin, M. (2016). Development of market mavenism traits: Antecedents and moderating effects of culture, gender, and personal beliefs. Journal of Business Research, 69(3), 1120-1129.

Levy, S. (1950). Figure drawing as a projective technique. In K.E. Abt, \& L. Bellak, (Eds). Projective Psychology (pp. 257-297). Grove Press, New York, NY.

Lin, K.-Y., \& Lu, H.-P. (2011). Why people use social networking sites: An empirical study integrating network externalities and motivation theory. Computers in Human Behavior, 27(3), 1152-1161.

Lincoln, Y. S., \& Guba, E. G. (1985). Naturalistic inquiry. Beverly Hills, CA: Sage.

McNeal, J. U. (1992). Kids as customers: $A$ handbook of marketing to children. New York, NY: Lexington Books.

McNeal, J. U., \& Ji, M. (2003). Children's visual memory of packaging. Journal of Consumer Marketing, 20(5), 400-427.

Marton, F. (1986). Phenomenograph: A research approach to investigating different understandings of reality. Journal of thought, 28-49.

Maxwell, J. A. (1997). Designing a qualitative study. The SAGE handbook of applied social research methods, 2, 214-253.

Maxwell, J. A. (2004). Qualitative research design: An interactive approach. London: Sage publications. 
O'Sullivan, S. R., (2015). The market maven crowd: Collaborative risk-aversion and enhanced consumption context control in an illicit market. Psychology \& Marketing, 32(3), 285-302.

Parmentier, G., \& Mangematin, V. (2014). Orchestrating innovation with user communities in the creative industries. Technological Forecasting and Social Change, 83, 40-53.

Rogers, E. M. (2003). Diffusion of Innovations (5th ed). New York, NY: Free Press.

Ruvio, A., \& Shoham, A. (2007). Innovativeness, exploratory behavior, market mavenship, and opinion leadership: An empirical examination in the Asian context. Psychology \& Marketing, 24(8), 703-722.

Slama, M. E., \& Williams, T. G. (1990). Generalization of the market maven's information provision tendency across product categories. Advances in Consumer Research, 17(1), 48-52.

Teimourpour, B., \& Hanzaee, K. H. (2011). The impact of culture on luxury consumption behaviour among Iranian consumers. Journal of Islamic Marketing, 2(3), 309-328.

Walsh, G., Gwinner, K.P., \& Swanson, S.R. (2004). What makes mavens tick? Exploring the motives of market mavens' initiation of information diffusion. Journal of Consumer Marketing, 21(2), 109-122.
Walsh, G., \& Mitchell, V. W. (2001). German market mavens' decision-making styles. Journal of EuroMarketing, 10(4), 83-108.

Walsh, G., \& Mitchell, V. W. (2010). Identifying, segmenting and profiling online communicators in an Internet music context. International Journal of Internet Marketing and Advertising, 6(1), 41-64.

Wiedmann, K. P., Walsh, G., \& Mitchell, V. W. (2001). The German manmaven: An agent for diffusing market information. Journal of Marketing Communications, 7(4), 195-212.

Yang, H. (2013). A cross-cultural study of market mavenism in social media: Exploring young American and Chinese consumers' viral marketing attitudes, eWOM motives and behavior. International Journal of Internet Marketing and Advertising, 8(2), 102-124.

Yoshida, D., Miyazawa, Jun-ichi, \& Takahashi, S. (2014). Role of community in user innovation generation and diffusion. Focusing on non-brand communities in the mountain climbing market. Technological Forecasting and Social Change, 88, $1-15$.

Zhang, J., \& Lee, W.N. (2014). Exploring the impact of self-interests on market mavenism and E-mavenism: A Chinese story. Journal of Internet Commerce, 13(3-4), 194-210. 


\section{Appendix A - Research procedures}

In this research, the authors used their skills and the rapport technique to obtain a trust-based insight into the lived experience of market mavens and their surrounding environment. Each of the people studied were given a blank sheet of A4 paper and were asked to depict for us a cyber-market maven together with the environment in which he/she lives and the things he/she thinks, using any stationary tool they liked and felt comfortable with. They were told that it did not matter whether the picture of the individual and its elements resembled the real world or not, and there was no right or wrong picture and no scores were going to be assigned to the pictures. Only the elements present in the picture and the interpretation thereof were of interest. Upon completion of the picture drawing, the authors thanked each participant for the time they spent on this study, and after a brief look, if some part of the picture was unreadable or unclear, the participant was requested to provide some explanation in this regard. The authors also let the participants know that they would be invited to an interview, particularly when interpreting the picture's elements. The data gathering of this study is inspired by Chan's (2006a) primary work.

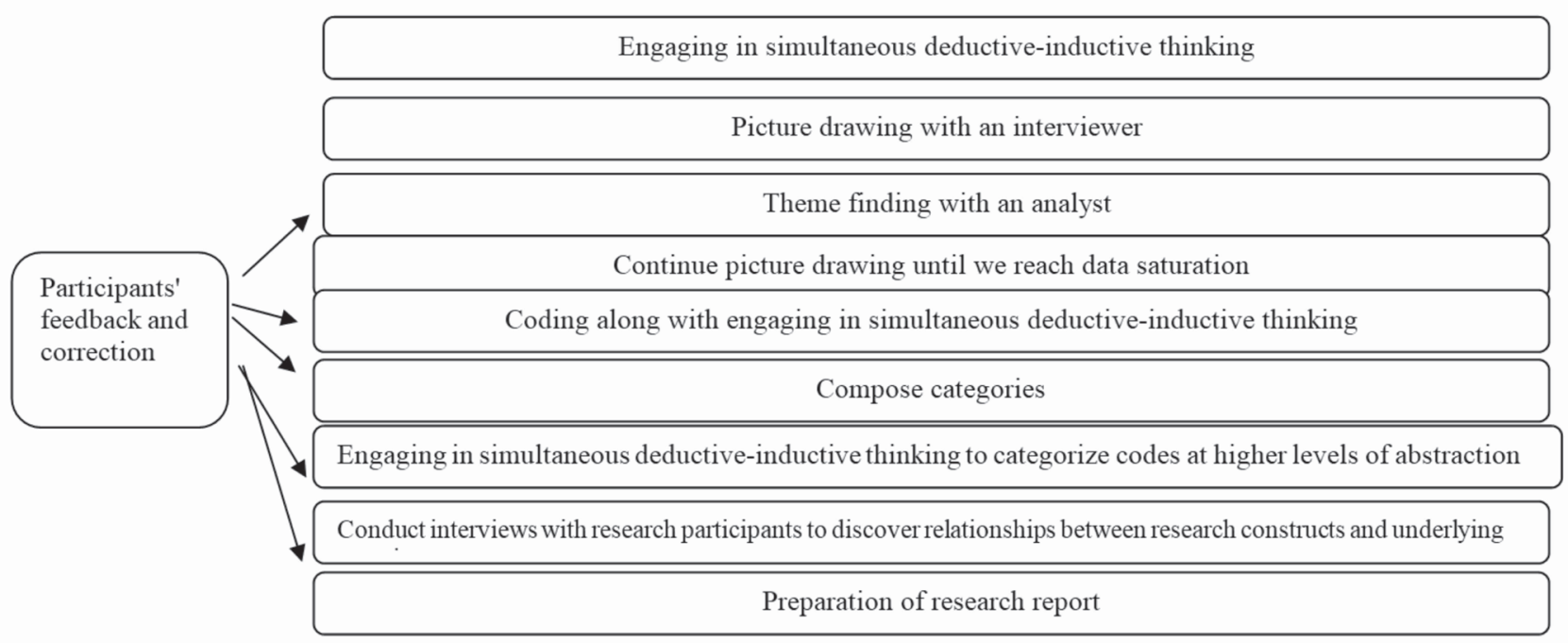

Data gathering and analysis diagram 


\section{Appendix B - Visual elements extracted from the pictures drawn by the informants}

\begin{tabular}{|c|c|c|c|c|c|c|c|c|c|c|c|c|c|c|c|c|c|c|c|c|c|c|c|c|c|}
\hline$\stackrel{\Xi}{3}$ & Category & 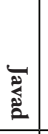 & 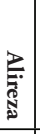 & 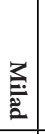 & 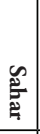 & \begin{tabular}{|l}
$\mathrm{N}$ \\
㐘 \\
\multirow{2}{*}{}
\end{tabular} & 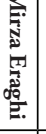 & 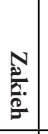 & . & 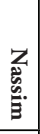 & 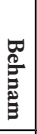 & $\begin{array}{l}\text { 2. } \\
\frac{0}{2} \\
\frac{2}{2}\end{array}$ & 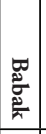 & 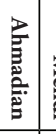 & $\begin{array}{ll}2 \\
0 \\
\frac{2}{2} \\
\end{array}$ & . & 䍘 & 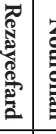 & 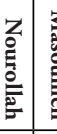 & 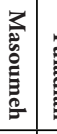 & 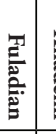 & 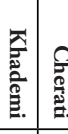 & & 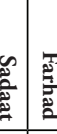 & 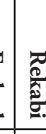 \\
\hline 1 & Celular & * & $*$ & * & $*$ & $*$ & & * & * & * & * & * & & & & & * & * & * & * & * & & & * & \\
\hline 2 & Tablet & & & $*$ & & $*$ & & * & & & & & & & & & & & & & & & & & \\
\hline 3 & Laptop & $*$ & $*$ & * & $*$ & $*$ & & $*$ & & $*$ & $*$ & $*$ & & & $*$ & & * & & & * & & & & * & \\
\hline 4 & Computador & & $*$ & & & & & & & & & & & & & & $*$ & & . & 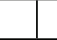 & & & * & & \\
\hline 5 & Informação & & & & $*$ & . & $*$ & & $*$ & $*$ & $*$ & . & $*$ & $*$ & * & $*$ & $*$ & & * & 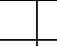 & 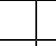 & & * $\quad *$ & * $\quad *$ & * \\
\hline 6 & Internet & & & & $*$ & $*$ & & & * & $*$ & & * & & & & & * & & * & * & $*$ & & * & * & * \\
\hline 7 & Modem \& Wi-Fi & & & & & & & $*$ & & & & & & & & & & $*$ & & * & * & & & & \\
\hline 8 & Jornal & & & & $*$ & & & & & & & & & & & & & & & & & & & * & \\
\hline 9 & TV & & & & & $*$ & & & & $*$ & $*$ & & & & & & & & & & & & & & \\
\hline 10 & Livro & & ${ }^{*}$ & * & ${ }^{*}$ & ${ }^{*}$ & & * & & ${ }^{*}$ & $*$ & & & 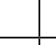 & ${ }^{*}$ & * & & * & & $*$ & & & & * & \\
\hline 11 & Óculos & & $*$ & $*$ & $*$ & $*$ & & $*$ & & . & . & 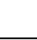 & & $*$ & * & & & $*$ & & & & & & * & \\
\hline 12 & Pesquisa & & & $*$ & & & $*$ & $*$ & & $*$ & $*$ & * & $*$ & $*$ & , & * & $*$ & & $*$ & & $*$ & & * & & * \\
\hline 13 & Papelaria & & & $*$ & & & & $*$ & & & & & & & & & & & & $*$ & & & & & \\
\hline 14 & Satélite & $*$ & ${ }^{*}$ & & & & & & & & & & & & & & & & & & & & & & \\
\hline 15 & Aviăo & $*$ & $*$ & & & & & & & & & & & & & & & & & & & & & & \\
\hline 16 & Planeta Terra & $*$ & $*$ & & & & & * & & & & & & & & & & & & & & & & & \\
\hline 17 & Produtos de Marca & & $*$ & ${ }^{*}$ & & * & * & & . & * & * & * & $*$ & ${ }^{*}$ & * & * & ${ }^{*}$ & * & & & * & \begin{tabular}{l|l}
$*$ & $*$ \\
\end{tabular} & * & & * \\
\hline 18 & Big Brain & & & & & & & & $*$ & & & & & & & & & & & & * & & & * & \\
\hline 19 & Árvores e Folhas & & & * & & & & & & & & & & & & * & & & & & & & & & \\
\hline 20 & Irrigaçăo por gotejamento & & & & & & & & & & $*$ & & & & & & & & & & & & & & \\
\hline 21 & Consumo de Combustível & & & & & & & & & & & * & & & & & & & & & & & & & \\
\hline 22 & Responsável e comprometido & & & & $*$ & & & & & & & & & & * & & & & & & & * & * & & * \\
\hline 23 & Letreiro & & & & & & & & & & & * & $*$ & & & & & & & & & * & & & \\
\hline 24 & Propaganda & & & & & & & & & & & & & & & & & & & & & & * & \begin{tabular}{l|l}
$*$ & $*$ \\
\end{tabular} & \\
\hline 25 & Propaganda e Sites de Empresas & & & & $*$ & & & & & & & $*$ & & & & & & & * & $*$ & & & \begin{tabular}{l|l}
$*$ & $*$ \\
\end{tabular} & * & * \\
\hline 26 & Tecnologias do Dia & & & & & ${ }^{*}$ & & & & ${ }^{*}$ & $*$ & & ${ }^{*}$ & & * & & & & * & * & & \begin{tabular}{l|l}
$*$ & $*$ \\
\end{tabular} & * $\quad *$ & * & * \\
\hline 27 & Capacidade de Resoluçáo de Problemas & * & $*$ & & & & * & * & & $*$ & $*$ & * & * & * & ${ }^{*}$ & & * & & ${ }^{*}$ & * & * & & * & & * \\
\hline 28 & Autoconfiança & * & & * & & & & & & & & & & & & & * & & & & * & & & & \\
\hline 29 & Rosto Feliz e Sorridente & & $*$ & * & $*$ & $*$ & * & ${ }^{*}$ & * & & & & $*$ & * & * & * & * & ${ }^{*}$ & * & & * & * & & & * \\
\hline 30 & Gosta de Ajudar & & $*$ & & $*$ & & * & & & $*$ & $*$ & & & & & * & & * & & & & & * & * & \\
\hline 31 & Mídias e redes Sociais & * & ${ }^{*}$ & * & & ${ }^{*}$ & & & & * & $*$ & * & ${ }^{*}$ & & * & & & & * & & & & & & \\
\hline 32 & Disseminaçăo de Informação e Experiência & & $*$ & * & $*$ & & $*$ & * & & $*$ & $*$ & & $*$ & & * & & ${ }^{*}$ & ${ }^{*}$ & * & & & & * & * & * \\
\hline 33 & Várias Marcas & & & * & & ${ }^{*}$ & & & & & & & & & & * & & & & & * & * & * & & \\
\hline 34 & Questóes Econômicas & $*$ & * & $*$ & $*$ & $*$ & & & * & ${ }^{*}$ & $*$ & * & $*$ & & & & & & & * & & * & & * & \\
\hline
\end{tabular}




\section{Authors:}

1. Milad Farzin, Ph.D. of Marketing, Science and Research Branch of Islamic Azad University, Tehran, Iran. E-mail: Milad.farzin@srbiau.ac.ir \& Milad.farzin85@gmail.com

\section{ORCID}

(iD) 0000-0002-4328-5734

2. Hossein Vazifedust, Ph.D. of Marketing, Science and Research Branch of Islamic Azad University, Tehran, Iran.

E-mail: vazifedusthossein18@gmail.com

\section{ORCID}

(iD) 0000-0002-6503-5808

3. Karim Hamdi, Ph.D. of Marketing, Science and Research Branch of Islamic Azad University, Tehran, Iran. E-mail: kareemhamdi18@gmail.com

ORCID

(iD) 0000-0003-3791-5311

\section{Contribution of each author}

\begin{tabular}{|c|c|c|c|}
\hline Contribution & $\begin{array}{l}\text { Milad } \\
\text { Farzin } \\
\end{array}$ & $\begin{array}{c}\text { Hossein } \\
\text { Vazifehdust }\end{array}$ & $\begin{array}{l}\text { Karim } \\
\text { Hamdi }\end{array}$ \\
\hline 1.Definition of research problem & $\sqrt{ }$ & $\sqrt{ }$ & $\sqrt{ }$ \\
\hline 2. Development of hypotheses or research questions (empirical studies) & $\sqrt{ }$ & $\sqrt{ }$ & \\
\hline \multicolumn{4}{|l|}{ 3. Development of theoretical propositions (theoretical work) } \\
\hline 4. Theoretical foundation/Literature review & $\sqrt{ }$ & & $\sqrt{ }$ \\
\hline 5. Definition of methodological procedures & & $\sqrt{ }$ & $\sqrt{ }$ \\
\hline 6. Data collection & $\sqrt{ }$ & & \\
\hline 7.Statistical analysis & $\sqrt{ }$ & $\sqrt{ }$ & \\
\hline 8. Analysis and interpretation of data & $\sqrt{ }$ & $\sqrt{ }$ & $\sqrt{ }$ \\
\hline 9. Critical revision of the manuscript & $\sqrt{ }$ & $\sqrt{ }$ & $\sqrt{ }$ \\
\hline 10. Manuscript writing & $\sqrt{ }$ & & \\
\hline 11. Other (please specify which) & & & \\
\hline
\end{tabular}

